\title{
When age does not harm innovative behavior and perceptions of competence: Testing interdepartmental collaboration as a social buffer
}

\author{
Laura Guillén $^{1} \quad$ Florian Kunze ${ }^{2}$
}

${ }^{1}$ ESMT Berlin, Berlin, Germany

${ }^{2}$ University of Konstanz, Konstanz, Germany

\section{Correspondence}

Laura Guillén, ESMT Berlin, Schlossplatz

1, Berlin 10178, Germany.

Email: laura.guillen@esmt.org

\begin{abstract}
Can older managers overcome stereotypes relating age to low competence? We integrate the literature on age and cognitive ability with research on innovation to explore whether-and if so, when-employees' age harms performance and promotability appraisals made by their supervisors. Multisource, time-lag data from 305 project managers indicate that the negative stereotypes can be explained through decreased innovative behavior. However, older employees are not always seen as poorer performers with less potential to be promoted due to their reduced innovative behavior. Rather, interdepartmental collaboration moderates these effects. Specifically, older employees with low interdepartmental collaboration are less innovative and receive worse performance and promotability appraisals than younger employees, but the "age handicap" vanishes when older employees collaborate with members of other departments. Organizations should foster formal or informal collaboration among units to prevent negative consequences of an aging workforce.
\end{abstract}

KEYWORDS

age, age stereotypes, innovative behavior, interdepartmental collaboration, performance appraisal, promotability

\section{INTRODUCTION}

The world population is aging at unprecedented speed (The World Bank, 2015), and age discrimination seems to be a serious concern in corporate life (Farrell, 2017). For example, two out of three workers above 40 years of age say they have seen or experienced age discrimination at work (American Association of Retired Persons, 2017). In the United States, age-related legal claims increased by more than 44\% from 1997 to 2014 (American Association of Retired Persons, 2014). One explanation is that age stereotypes depict older employees as poorer performers (Cuddy, Norton, \& Fiske, 2005) and less promotable (Hansson, DeKoekkoek, Neece, \& Patterson, 1997; Rosen \& Jerdee, 1976; Shore \& Goldberg, 2005) than younger ones. Although information is gradually accumulating on older employees' higher likelihood of receiving unfavorable personnel decisions compared to younger employees, such as getting fewer training opportunities and reduced callback rates in hiring processes (Neumark, Burn, \& Button, 2017; Van der Heijden, 2006; Van Veldhoven \&
Dorenbosch, 2008), research on what drives age stereotypes is rather limited. Not surprisingly, scholars have called for work on this topic in order to help organizations understand and manage age biases in the workplace (Kulik, Ryan, Harper, \& George, 2014; Kunze, Boehm, \& Bruch, 2013; Posthuma \& Campion, 2009). This paper aims to shed light on this intriguing issue by identifying not only whether but why and when age is associated with negative age stereotypical perceptions of low competence-that is, low performance and promotability appraisals made by supervisors.

One of the reasons often adduced why older workers are perceived as less competent than their younger counterparts is that they are less open to new experiences (Jones \& Meredith, 1996), more concerned with realizable pragmatic achievement (Mumford \& Gustafson, 1988), and more resistant to change (Morris \& Venkatesh, 2000). All of this ultimately harms their innovative behavior (Rosen \& Jerdee, 1976; Van Dalen, Henkens, \& Schippers, 2009), defined as the production or adoption and implementation of useful novel ideas (Kanter, 1988; Van de Ven, 1986). When individuals are perceived as lacking 
innovative skills, judgments of personal agency-or competence-drop (Fiske, Cuddy, \& Glick, 2007). However, is it true that older employees are less innovative in the first place? Results seem to suggest so, but there are plenty of examples of older employees who are successful innovators. In this paper, we use cognitive ability theory to explore whether and when the negative relationship between age and perceptions of being competent at work can be explained through decreased innovative behavior. We incorporate a social innovation angle to obtain a more nuanced view of these relationships. In particular, we suggest that knowledge-sharing mechanisms, such as collaborating with other employees across different business units and departments (Ancona \& Caldwell, 1992a, 1992b), reduce the negative effects of the decline in cognitive ability of older workers on innovative behavior and on performance and promotability evaluations.

Cognitive ability theory (Cattell, 1943) distinguishes between fluid intelligence (Gf), which is related to abstract reasoning, memory, and processing of novel information, and crystallized intelligence (Gc), which is defined as domain knowledge acquired through education and experience. Because cognitive ability (Gf) is related to innovation (Nusbaum \& Silvia, 2011), and because cognitive ability declines with age (Schaie, 1996), one might expect age to reduce innovative behavior. However, research on this relationship has found inconsistent results (Eder \& Sawyer, 2007; Ng \& Feldman, 2008, 2010). We propose that both age-related decline in Gf and age-related increase in Gc have effects on innovative behavior, which are channeled into performance and promotability appraisals. In particular, we expect that the decline in Gf may be partially or fully offset by older adults' enhanced experience-based knowledge, which refers to the level of sophistication and complexity of knowledge in a given and specific job. Experience-based knowledge is required for innovative behavior, not only as a basis for recombination of ideas but also for the capacity to understand what is novel, appropriate, and useful (Amabile, 1983). Yet there is no guarantee that individuals will use their experiencebased knowledge in ways that ignite innovative behavior (Cirillo, Brusoni, \& Valentini, 2013; Dane, 2010; Hargadon \& Bechky, 2006). Contrarily, studies of professional employees have shown that deep and specialized knowledge can lead to routine contributions, inertia, and conformity (March, 1991).

Spanning intraorganizational boundaries, reaching out, and collaborating with employees from outside the focal groups in which they usually operate (Ancona \& Caldwell, 1988, 1992a; Perry-Smith \& Mannucci, 2015; Taylor \& Greve, 2006) are key to overcoming inertia and promoting innovation (Tortoriello \& Krackhardt, 2010). When individuals span intraorganizational boundaries and collaborate with others across distinct business areas or departments-that is, high interdepartmental collaboration, ${ }^{1}$ they gain a broader knowledge on work-related issues and access to diverse ideas and perspectives that equip them to apply their deep experience-based job knowledge in innovative ways (Allen \& Cohen, 1969; Ancona \& Caldwell, 1992a; Taylor \& Greve, 2006). We therefore predict that older workers who strongly engage in interdepartmental collaboration will be able to capitalize on their enhanced experience-based knowledge to compensate for the effect of the loss of cognitive ability (Gf) on their innovative behavior. Figure 1 depicts our overall conceptual model.
We enrich the literature on age and innovation in the workplace in at least three ways. First, we contribute to the literature on age stereotypes and discrimination in the workplace ( $\mathrm{Ng} \&$ Feldman, 2012; Posthuma \& Campion, 2009) by identifying the innovative behavior of employees as a core mediator between age and organizational promotion and performance appraisal. Companies might benefit from our research by gaining information on how to tailor the work environment to avoid the negative consequences of an aging workforce. Second, we aim to clarify the theoretical and empirical inconsistencies in the literature regarding the relationship between age and innovationrelated behaviors in the workplace. For this purpose, we formulate and test a hypothesis using arguments from cognitive psychology (Horn \& Cattell, 1967) to explain the potential innovation deficits of older employees. Finally, we match research on age in the workplace with ideas from the literature on social networks and intergroup innovation (Alexander \& Van Knippenberg, 2014; Ancona \& Caldwell, 1992a; Tortoriello \& Krackhardt, 2010). In particular, we investigate interdepartmental collaboration as a social buffering mechanism that reduces the innovation deficits of older employees. In doing so, we hope to help build a better conceptual and empirical base for the thus-far limited and scattered literature on age and innovativeness in the workplace (Ng \& Feldman, 2008, 2012; Warr \& Fay, 2001).

\section{THEORY DEVELOPMENT}

\subsection{Innovative behavior}

Individuals' innovative behavior (Powell, Koput, \& Smith-Doerr, 1996) can be conceived as a search process (Campbell, 1960; Romer, 1993) that includes at least three stages (Singh \& Fleming, 2010): "variation" or generating new ideas; "selection" or evaluating ideas to reject poor outcomes and identify the most promising novelties; and "retention" or implementing and adopting ideas. Because innovative behavior involves not only generating ideas (what is traditionally seen as creativity; see, e.g., Amabile, 1988) but also discussing and selecting viable ideas, championing them within the organization, and getting things done, it is inseparable from social processes (Brown \& Duguid, 1991; Grosser, Venkataramani, \& Labianca, 2017; Perry-Smith \& Mannucci, 2015).

\subsection{Age and innovative behavior in organizations}

Cattell's $(1943,1987)$ distinction between fluid (Gf) and crystallized (Gc) forms of intelligence has been widely used to explain age-related gains and losses in cognitive functioning associated with creativity (i.e., the idea generation component of innovative behavior).

\subsubsection{Losses}

Gf, which is related to abstract reasoning, memory, and processing of novel information, peaks in an individual's early 20s and then declines over the life course (Craik \& Bialystok, 2006; Schaie, 1994). Because idea generation involves substantial Gf effort and less Gc, the decline in cognitive ability primarily affects the "variation" component of innovative behavior. Recent psychological research has compellingly 


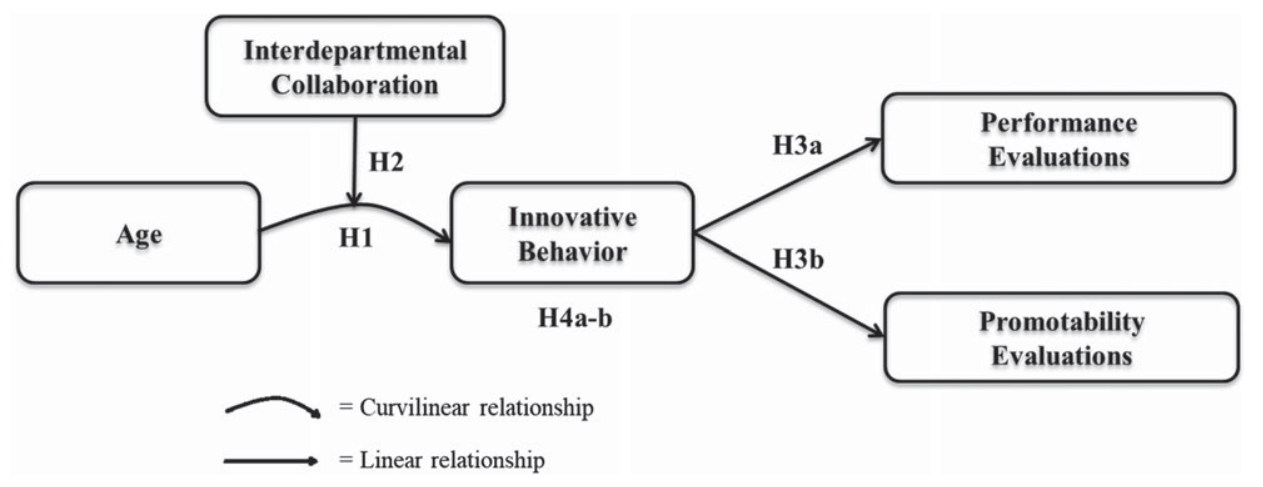

FIGURE 1 Theoretical model

demonstrated that Gf is central to being creative $(r=0.20)$ (Nusbaum \& Silvia, 2011). Reduced speed of information processing and a lower level of complexity in older adults (Ruth \& Birren, 1985), together with a decrease in working memory and problem-solving abilities (Horn \& Cattell, 1967; Park, 1997), can explain age differences in creativity.

However, similar to the age-Gf relationship, the age-creativity relationship is nonlinear. Research across varied disciplines, including science, arts, and philosophy (see Simonton, 1988, for a review), has found that this relationship seems to follow an inverted backward J function: creativity rises in youth until it reaches a peak and thereafter declines gradually (Lehman, 1962; Simonton, 1988).

\subsubsection{Growths}

In contrast to Gf, Gc tends to show a (monotonic) positive relationship with age (Kanfer \& Ackerman, 2004). The knowledge accumulated through a lifetime of experience and learning by doing (Gc) can elevate innovative behavior (Mascitelli, 2000; Nusbaum \& Silvia, 2011). Experience-based knowledge leads to a complex and thorough understanding of problems that facilitates out-of-the-box thinking in certain tasks and domains (Laursen \& Salter, 2006). This suggests that the more knowledgeable and experienced workers are, the more potential they have to innovate.

Intuitively, it then seems plausible that the enhanced knowledge of older workers $(\mathrm{Gc})$ may compensate for their decline in cognitive ability (Gf) depending on the demands of the job domain considered. Simonton (1988) suggests that the peak of the age-creativity curve is reached at different age values depending on the discipline under consideration. In some professions, such as pure mathematics, theoretical physics, piloting, or controlling air traffic, creativity primarily makes high demands on Gf, and these professions are therefore characterized by relatively early peaks (around the early 30 s or even the late 20 s, suggesting that the age-Gf and age-creativity curves run almost in parallel in these job domains). In contrast, teachers, attorneys, or managers (Ackerman, 1996) rely highly on experience-based knowledge, so even if Gf declines with increasing age, concomitant increases in Gc can more than compensate. In these latter domains, the peak of the curve shifts to the right (Haans, Pieters, \& He, 2016), and the negative effects of age on creativity manifest only at higher age values, often well into middle age (late 30 s or early 40 s) (Kanfer \& Ackerman, 2004; Simonton, 1988). See Figure 2a for a visual representation of the theorized effects. Thus, these effects, driven by the idea generation component of innovative behavior, suggest that, for managers,

Hypothesis 1: Age has a nonlinear relationship with innovative behavior so that a decline in innovative behavior manifests only after the late 30 s or early 40 s.

Beyond its effects on idea generation, experience-based knowledge can benefit innovative behavior (Mascitelli, 2000; Nusbaum \& Silvia, 2011) because it facilitates gaining support across the organizational structure to implement novel ideas (Zahra \& George, 2002). However, studies using organizational samples have shown that this positive effect does not always occur. Experience-based knowledge can trigger negative consequences such as inertia, conformity, and routine contributions (Dane, 2010; March, 1991). Unlike younger employees, older ones are more likely to rely on routines that have proved successful in the past (Katz \& Allen, 1982) and to become more exploitative (Cirillo et al., 2013), habits that can ultimately undermine their capacity to innovate (Maidique \& Zirger, 1985). Moreover, the well-developed experience-based knowledge of older workers inhibits the reintegration and reorganization of ideas due to its stability, prior use, and automaticity (Barsalou, 1983), so much so that they can become inflexible and resistant to modifying their ways of doing things (Dane, 2010). The question, then, is when older workers' enhanced experience-based knowledge benefits or hinders their innovative behavior.

\subsection{The moderating role of interdepartmental collaboration}

Disparate knowledge and expertise helps individuals overcome inertia and conformity (Cirillo et al., 2013; Mannucci \& Yong, 2018). Within an individual's mind, knowledge is organized in schemas-that is, cognitive structures containing knowledge about a specific domain and the linkages with other domains (Fiske \& Taylor, 1991). Focusing attention on tasks and events outside one's expertise domain increases the flexibility of individuals' knowledge structures (Dane, 2010; Mannucci \& Yong, 2018). A core assumption in the innovation literature is that it is breadth, rather than only depth, of knowledge and experience that matters for being innovative in organizations 
(a) The effect of cognitive decline (Gf)

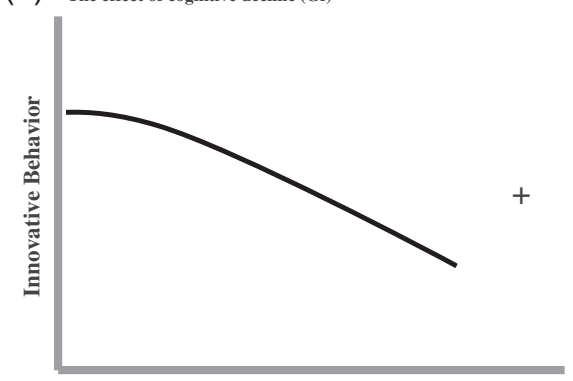

Age (years)
The effect of enhanced knowledge (Gc)

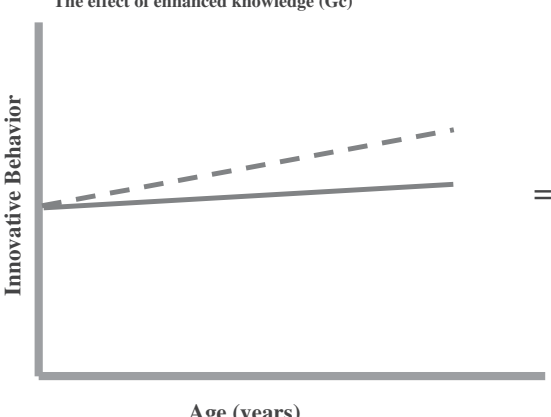

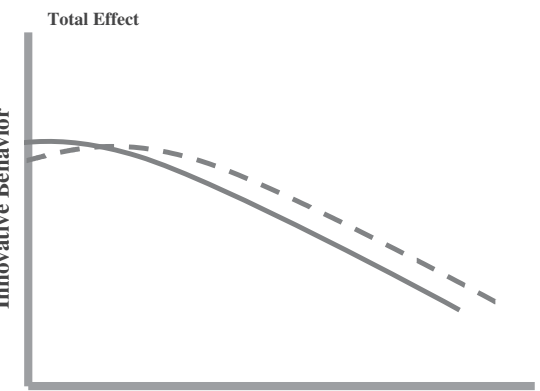

Age (years)

- - In domains that entail high levels of Gc, such as managerial jobs, technical fields, architecture

In domains that require lower levels of Gc, such as pure mathematics, physics, or air traffic controllers

(b) The effect of cognitive decline (Gf)

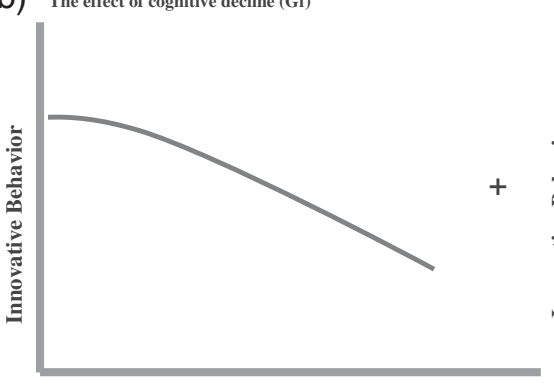

Age (years)
The effect of enhanced knowledge $(\mathrm{Gc})$

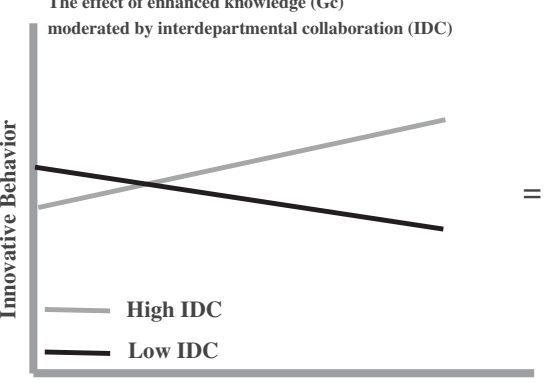

Age (years)

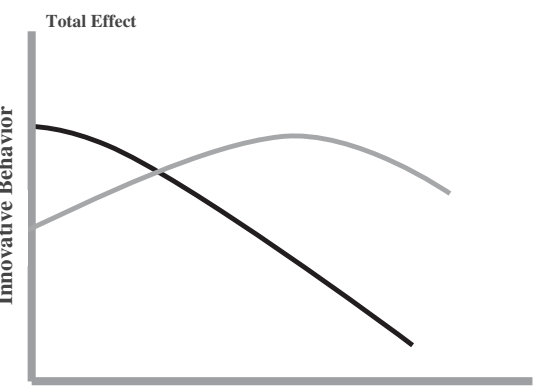

Age (years)

FIGURE 2 (a, b) Illustration of the additive combination of the latent mechanisms (Gf and Gc) that shape the relationship between age and innovative behavior. (a) Hypothesized age effects (driven by Gf, Gc, and total) on innovative behavior. (b) Hypothesized age effects on innovative behavior moderated by interdepartmental collaboration (IDC). Note. The Gf component illustrates the effect of the decline of cognitive ability on innovative behavior, whereas the Gc component illustrates the effect of enhanced experience-based knowledge on innovative behavior. Because the average age of first-time managers tends to be around 30 years, the age-innovative behavior curves depicted here correspond to an age range between late 20 s and retirement age

(Taylor \& Greve, 2006). Sharing knowledge mechanisms, such as collaborating with other employees from outside their business areas or departments, facilitates the incorporation of distinct and multiple domains into an individual's know-how (Ancona \& Caldwell, 1992a).

The fact that innovative behavior is boosted when individuals gain access to diverse knowledge by cooperating across different functional areas of the organization, that is, high interdepartmental collaboration, has been well established in the literature (Alexander \& Van Knippenberg, 2014; Amabile, 1993; Ancona \& Caldwell, 1992a, 1992b; Perry-Smith, 2006; Tortoriello \& Krackhardt, 2010). Singh and Fleming (2010) have dismantled the myth of the "lonely inventor," showing that innovation, measured through high-impact patents, is more likely to occur when employees with diverse functional experience cooperate closely. We argue that, regardless of any potential cognitive deficits, enhanced Gc of older workers improves their innovative behavior if they are high in interdepartmental collaboration because it provides substantial benefits throughout the variation, selection, and retention stages of innovation.

Collaborating across departments leads to informational advantages (Allen \& Cohen, 1969; Ancona \& Caldwell, 1992a, 1992b; Heavey, Simsek, \& Fox, 2015). Such collaborations stir up knowledge repositories and facilitate the understanding of new information and challenges, which can lead to novel combinations of knowledge spread across business units (Zhou \& Li, 2012). Exposure to a breadth of knowledge from others promotes mutual learning and results in more flexible and complex cognitive schemas that enhance an individual's creative ability (Perry-Smith \& Mannucci, 2015). Moreover, individuals are likely to encounter exceptions and counterexamples to their approaches to overcome their work challenges (Langer, 1989). Thus, access to new ideas and information from a variety of sources can enhance individuals' generation of novel ideas in the variation stage (Carmeli, Gelbard, \& Reiter-Palmon, 2013).

Moreover, actively collaborating with others can also boost innovation in the selection and retention stages because it serves as a means for building social support and obtaining the resources needed to implement novel ideas (Howell \& Shea, 2006; Sandberg, 2007). That is, although older workers may not be ultimately responsible for idea generation, they can team up with others and focus on supporting innovative collective efforts and getting things done. It is in these occasions that their organizational knowledge and experience can constitute a strategic advantage.

By collaborating with employees from different areas of expertise, older employees can use their specialized job knowledge to create new work patterns that facilitate social innovation processes (Cirillo et al., 2013; Katz, 1981) related to discussing and selecting viable ideas and to championing them within the organization. They can use their enhanced experience-based knowledge to select appropriate solutions to resolve the demands of emerging complex situations 
(Hargadon \& Bechky, 2006). Thus, when older employees come together and collaborate with others, they broaden the understanding of complex organizational problems and are in a better position to use their experience-based knowledge to identify the most promising solutions given the context in which they operate.

Collaboration also informs employees about new solutions and opportunities to implement innovative ideas (Ancona \& Caldwell, 1992a; Hoegl, Weinkauf, \& Gemuenden, 2004; Teigland \& Wasko, 2003; Tortoriello \& Krackhardt, 2010). When older employees collaborate with members of different organizational units, they are able to figure out "who knows what" in the organization (Austin, 2003). Older workers can benefit from their experience to navigate within the organizational social structure and play an active role in sharing relevant information, promoting new ideas, and looking for the required support to implement them. This also makes it easier for them to solicit help when needed, which precipitates positive learning attitudes and, subsequently, innovative behavior (Hargadon \& Bechky, 2006). Collaborating and sharing perspectives with others can therefore stimulate older employees to use their specific and domain knowledge and expertise to resolve problems successfully also during the implementation stage.

Thus, we expect that interdepartmental collaboration moderates the linear effect driven by the Gc mechanism, while it does not affect the nonlinear effect driven by the decline of Gf. Compared to the base case (Figure 2a), Figure $2 b$ illustrates how interdepartmental collaboration alters the slope of the age-innovative behavior relationship driven by Gc. When interdepartmental collaboration is high, the slope is positive and steep enough to compensate for the decline of cognitive ability (Gf) so that the total negative effect of age on innovative behavior manifests at higher age values, shifting the turning point of the curve to the right (see Haans et al., 2016, on moderation of nonlinear relations):

Hypothesis 2: Interdepartmental collaboration moderates the nonlinear relationship between age and innovative behavior so that the decline in innovative behavior after the late 30 s or early 40 s takes longer to manifest under high levels of interdepartmental collaboration than under low levels of interdepartmental collaboration.

\subsection{Age stereotypical perceptions at work}

Age stereotypes portray older workers as less competent than younger ones (Cuddy et al., 2005). Competence is one universal dimension individuals rely on to judge others during their social interactions (Fiske et al., 2007). It refers to human agency and includes goal attainment, achievement, mastery, power, and ambition for personal advancement (Eagly \& Karau, 2002). In achievement-oriented contexts, age stereotypes manifest in older workers who are seen as poorer performers (Cuddy et al., 2005) and as plateaued employees (Near, 1980; Shore \& Goldberg, 2005) compared to younger ones. (Although performance and promotability go often hand in hand, employees may plateau independent of their performance.)
We propose that it is due to the decrease in innovative behavior that older workers are punished in performance and promotability evaluations. Innovators elicit respect (Fiske et al., 2007) and are thus likely to be positively perceived by upper managers. Not surprisingly, being innovative, original, and creative has often been invoked as an essential requirement for being perceived as competent at work because innovators are seen as visionaries, ambitious, charismatic, influential, capable, and confident (Conger \& Kanungo, 1987; Zaleznik \& Kets de Vries, 1975).

Regarding performance evaluations, the decreased innovation older workers are perceived to have harms performance appraisals made by their supervisors. Innovative behavior contributes to employees' overall effectiveness (Welbourne, Johnson, \& Erez, 1998). Aryee, Walumbwa, Zhou, and Hartnell (2012) have shown that innovative behavior relates to task accomplishment, and Bartram (2005) found that innovation-related behavior predicted perceptions of overall job performance $(\beta=0.12)$ above and beyond other task-related (e.g., organization and problem analysis) and contextual skills (e.g., adaptability, communication). Miron, Erez, and Naveh (2004) also showed that employee innovation relates positively to perceptions of job performance quality and efficiency.

With respect to promotability, because older employees tend to be concerned with job security, they are less open to new experiences and less willing to take the risks needed to learn new things and innovate (Kooij, De Lange, Jansen, Kanfer, \& Dikkers, 2011). Consequently, they might end up receiving fewer increasingly new and challenging assignments, and their careers stagnate (Feldman \& Weitz, 1988). When individuals do not engage in innovative behavior, they avoid change and learning opportunities, which reduces their visibility and exposure to senior management and their likelihood of upward mobility (Schein, 1978). Their lack of change-oriented attitudes is also associated with a lower need for self-advancement, which has been shown to decrease the upward mobility in their careers (Slocum, Cron, Hansen, \& Rawlings, 1985).

Our theoretical model predicts an indirect negative effect of age on performance and promotability evaluations, mediated via innovative behavior and moderated by interdepartmental collaboration. In the first part of our model, we predict that older employees are likely to be handicapped in comparison to younger ones but only if they do not collaborate across departments. Collaboration may reduce this age handicap, allowing older employees to reach levels of innovative behavior comparable to those of young employees-levels that shield them against age stereotypes of low competence and, ultimately, against low performance appraisals and promotability assessments:

Hypotheses 3a and 3b: Innovative behavior has a positive relationship with supervisors' performance $(\mathrm{H} 3 a)$ and promotability $(\mathrm{H} 3 b)$ evaluations.

Hypotheses 4a and 4b: Interdepartmental collaboration moderates the indirect effect of employees' age on supervisors' performance $(\mathrm{H} 4 \mathrm{a})$ and promotability $(\mathrm{H} 4 \mathrm{~b})$ evaluations through innovative behavior such that the decline 
in innovative behavior after the late 30 s or early 40 s takes longer to manifest under high levels of interdepartmental collaboration than under low levels of interdepartmental collaboration.

\section{METHOD}

\subsection{Sample and design}

We collected multisource and time-lagged data from an international social work organization whose mission is to build a better, more just society. Participants were project managers in different departments that were analogous to different functional units, such as culture, institutional relations, social management, research and knowledge, and education. Although the organization operates worldwide and has offices on three continents, all participants in this study were based in the organization headquarters located in Southern Europe. We collected data from personnel archives and from online surveys intended to support a developmental initiative. To increase the participation rate, we aimed to minimize the number of survey items per dimension.

We operationalized perceptions of competence through performance evaluations (measured via performance appraisals by the supervisor and variable pay allocations by upper management) and promotability evaluations by the supervisor. The human resources (HR) director invited the 338 project managers in the organization to complete the initial survey. At Time 1, we measured participants' interdepartmental collaboration and their age (taken from personnel records). One month later, at Time 2, participants were rated by their supervisors on innovative behavior. Also at Time 2, supervisors recorded their performance appraisals and promotability decisions using a different online survey to minimize concerns about common method variance (Conway \& Lance, 2010). Decisions made by upper management on variable pay allocation were measured 6 months later (Time 3), at the end of the organization's operating year, and were obtained from the human resource department records. Human resource managers, senior managers, and work unit managers held end-of-the-year review meetings to discuss their perceptions of the performance of each participant and decide on variable pay (i.e., annual bonuses) based on goal accomplishment. These decisions were cross-checked by managers of different areas and then by managers within a given area to ensure consistency in the decisions across work units.

Complete data were available for 305 participants (a 90\% response rate). The participants ( $73 \%$ female) were, on average, 45.20 years old $(S D=7.76)$, ranging from 27 to 62 years, and had 14.53 years of work experience in the organization.

\subsection{Measures}

Unless we specify otherwise, respondents indicated the extent to which they agreed with each item on a 7-point Likert-type scale anchored at $1=$ not at all and $7=$ very much. Detailed wording for all measures is presented in the appendix.

\subsubsection{Age $\left(\mathrm{T}_{1}\right)$}

Age was measured in years as stated in the organization's personnel records.

\subsubsection{Interdepartmental collaboration $\left(T_{1}\right)$}

Participants rated the extent to which they collaborated across departments within their organization during their daily work by responding to four items adapted from Powell and colleagues' definition of external collaborations (Powell et al., 1996). A sample item is "I collaborate with members of other departments of the organization" $(\alpha=0.78)$.

\subsubsection{Innovative behavior $\left(\mathrm{T}_{2}\right)$}

Participants' innovative behavior was assessed by the direct supervisor of each employee on the six-item innovation scale developed by Scott and Bruce (1994). Supervisory ratings are the proxy most commonly used to measure work behaviors in organizations (Arvey \& Murphy, 1998); like other scholars before us (Carnabuci \& Diószegi, 2015; Scott \& Bruce, 1994; Welbourne et al., 1998), we relied on supervisory ratings of innovative behavior. A sample item is "Generates creative ideas" ( $\alpha=0.95)$.

\subsubsection{Performance appraisals $\left(\mathrm{T}_{2}\right)$}

Direct supervisors were asked to rate the extent to which each participant had accomplished his or her job goals and responsibilities during the previous operating period by selecting the appropriate response on the following scale: (a) needs development, (b) effective, (c) highly effective, and (d) exceptional. See details of each category in Appendix A.

\subsubsection{Promotability evaluations $\left(\mathrm{T}_{2}\right)$}

Direct supervisors were asked to indicate whether participants were ready to take over the next level of responsibilities within the organization ( 0 = no; 1 = yes).

\subsubsection{Variable pay allocations $\left(\mathrm{T}_{3}\right)$}

Six months later, human resource managers, senior managers, and area managers attended end-of-the-year annual review meetings to distribute annual bonuses (in Euros) based on employees' goal achievement.

\subsubsection{Control variables}

We controlled for a number of factors that might relate to either our mediator and/or our outcome variables. First, we controlled for other demographic factors, such as gender ( 0 = male, 1 = female), organizational level $(0=$ employees in roles without people management responsibilities, 1 = employees in roles with people management responsibilities), and tenure (integers). We also controlled for supervisor age (integers).

The social cognition literature (Fiske et al., 2007) states that interpersonal liking influences the accuracy of supervisors' evaluations of their employees, including job performance evaluations, promotion opportunities, and pay raises (Cardy \& Dobbins, 1986). To control for these effects, at Time 2 , we asked supervisors to rate their employees 
on the four-item scale of interpersonal liking developed by Wayne and Ferris (1990). Sample items are "I like working with this person" and "Working with this person is a pleasure" ( $\alpha=0.93)$.

\section{ANALYSES}

We ran regressions to test Hypotheses 1, 2, and 3a and b. Because not all of our final dependent variables were continuous, we used logistic regressions, which are best suited to regressions with binary (perceived promotability) and ordinal (performance appraisals) dependent variables (Rogers, 1993). Because the data were nested (participants were grouped into 44 teams, each with a different direct supervisor), we conducted conservative tests of the predictions by specifying clustered standard errors (Rogers, 1993) at the team level. To assess Hypotheses $4 a$ and b, we used generalized structural equation models (SEM; Bollen, 1989), which have been shown to have advantages in testing complex mediation models (Cheung \& Lau, 2008; Hoyle \& Smith, 1994; Saris \& Gallhofer, 2007). ${ }^{2}$

Being aware of the misuse of controls in organizational research, we followed Becker's (2005) recommendations and tested the model with and without control variables to be able to discard controls as alternative explanations of our findings. We centered the predictors (age, interdepartmental collaboration, and innovative behavior); we also standardized variable pay before running our analyses to avoid multicollinearity problems due to its scale format (Edwards, 1994).

\section{$5 \quad$ RESULTS}

\subsection{Measurement models}

To verify the hypothesized factor structure of our multi-item variables, we conducted confirmatory factor analyses (Bentler \& Dudgeon, 1996). We first assessed a five-factor model, including self- and other-assessed variables (i.e., innovative behavior, interdepartmental collaboration, performance ratings, promotability evaluations, and variable pay allocations), which showed sufficient fit properties $\left(\chi^{2}(61)=169.62\right.$, RMSEA $=0.07, \mathrm{CFI}=0.95$, SRMR $=0.06$; RMSEA: root mean square error of approximation, $\mathrm{CFI}$ : comparative fit index, SRMR: standardized root mean square residual). A three-factor model that included all items rated by the supervisors as the same underlying dimension showed a significant drop in fit compared to the five-factor model $\left(\Delta \chi^{2}=30.16, \Delta d f=3, p<0.001\right)$. Finally, a one-factor model including all items as one underlying dimension showed a significantly worse fit than the five-factor model $\left(\Delta \chi^{2}=356.61, \Delta \mathrm{df}=4\right.$, $p<0.001)$. These results support the distinctiveness of our focal variables.

\subsection{Descriptive statistics}

Means, $S D$, correlations, and reliabilities appear in Table 1. Age was negatively related to innovative behavior $(r=-0.14, p<0.05)$ but had no significant relationship with interdepartmental collaboration

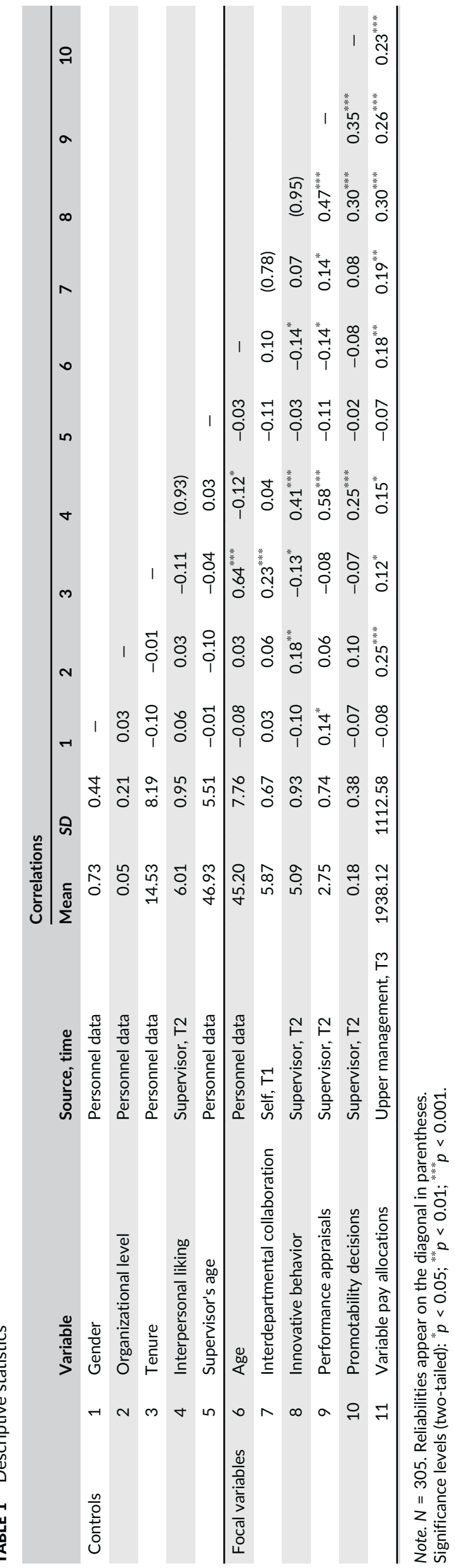


$(r=0.10, n s$.$) . As we expected, innovative behavior had a positive$ relationship with all dependent variables $(0.47,0.30$, and 0.30 , $p<0.001$, for performance ratings, promotability evaluations, and variable pay allocations, respectively).

\subsection{Hypothesis testing}

To explore Hypothesis 1, we first tested the linear and curvilinear relationships between age and innovative behavior, given, respectively, by the following equations:

$$
\begin{gathered}
y_{i}=\beta_{0}+\beta_{1} \cdot x_{i}+e \\
y_{i}=\beta_{0}+\beta_{1} \cdot x_{i}+\beta_{2} \cdot x_{i}^{2}+e,
\end{gathered}
$$

where, for each individual $i, y_{i}$ is innovative behavior, and $x_{i}$ is age. Table 2 shows the progression of testing these models. The models with and without control variables yielded identical results with respect to our hypotheses. To obtain the best estimates of our coefficients, we used the model without impotent controls in subsequent analyses.

In Model 1, the linear term of age had a negative and significant effect on innovative behavior $(-0.015, p=0.05)$. In Model 2, both age $(-0.016, p=0.03)$ and age-squared $(-0.001, p=0.02)$ were negatively and significantly related to innovative behavior. The quadratic model (Model 2) fitted the data better than the linear model (Model $1)$, as is implied by a significantly higher $R^{2}(\Delta R=0.01 ; F(1,43)=5.72$, $p=0.02)^{3}{ }^{3}$ These findings suggest that the negative relationship between age and innovative behavior is curvilinear, rather than linear. The shape of this interaction, depicted in Figure 3, is consistent with that found by previous studies (see, e.g., Simonton, 1988, for a review). The vertex (or inflection) point of the curve was estimated at -8 of the centered age variable, which corresponded to 37.22 years. ${ }^{4}$

To identify the age values at which the relationship between age and innovative behavior was negative, we compared the point estimates at high, intermediate, and low age values within the age range of our sample (minimum $=27$; maximum $=62$ years) against each other (Baer \& Oldham, 2006; Edwards \& Parry, 1993; Janssen, 2001). ${ }^{5}$ The slopes (i.e., differences in innovative behavior) between points at low and intermediate age values with respect to the vertex were not significant $(F(1,43)=1.67$ and 0.19 , ns., respectively). In contrast, the slope at high age values was negative and significantly different from zero: $F(1,43)=9.13, p=0.004$. These results are in agreement with Hypothesis 1 and suggest a negative nonlinear relationship between age and innovative behavior only at high age values (higher than 41 years old).

To explore Hypothesis 2, next, we assessed the relationship between age and innovative behavior moderated by interdepartmental collaboration. Following the principles of moderated regression (Aiken \& West, 1991), we added interdepartmental collaboration and its product with the linear and quadratic age terms in Equation 2, which resulted in the following expression:

$$
y_{i}=\beta_{0}+\beta_{1} \cdot x_{i}+\beta_{2} \cdot x_{i}^{2}+\beta_{3} \cdot w+\beta_{4} \cdot x_{i} \cdot w+\beta_{5} \cdot x_{i}^{2} \cdot w_{i}+e,
$$

where, for each individual $i, y_{i}$ is innovative behavior, $x_{i}$ is age, and $w_{i}$ is interdepartmental collaboration.

The moderating effect of interdepartmental collaboration is captured by the two terms $\left(x_{i} \cdot w_{i}\right.$ and $\left.x_{i}^{2} \cdot w_{i}\right)$ as a set (Edwards \& Parry, 1993). More precisely, the moderation can be tested by assessing whether the $R^{2}$ from Equation 3 is significantly larger than the $R^{2}$ from Equation 2. The increment in $R^{2}$ due to the inclusion of the moderator in the model was significant $\left(\Delta R^{2}=0.03, F(3,43)=2.92, p=0.04\right)$, providing initial support to Hypothesis 2 . We hypothesized that only the linear function (Equation 4) of the additive combination of latent mechanisms (i.e., Gc-related; see Figure 2b), explaining the "ageinnovative behavior" relationship, is affected by interdepartmental collaboration. In contrast, we expected the quadratic effect to remain unaffected (Equation 5 reflects the effect of declining cognitive ability, Gf, on innovative behavior. See Haans et al., 2016, on moderation of nonlinear relationships).

$$
\begin{gathered}
\text { Linear function }=a_{0}+\left(a_{1}+w\right) \cdot x_{i}+e \\
\text { Quadratic function }=b_{0}+b_{1} \cdot x_{i}+\beta_{2} \cdot x_{i}{ }^{2}+e
\end{gathered}
$$

Results from Equation 3, including both the linear and quadratic functions, are presented in Model 3 of Table 2 . In this model as well,

\begin{tabular}{|c|c|c|c|c|c|c|}
\hline \multirow[t]{2}{*}{ Variables } & \multicolumn{2}{|c|}{ Model 1: linear relationship } & \multicolumn{2}{|c|}{ Model 2: nonlinear (quadratic) relationship } & \multicolumn{2}{|c|}{ Model 3: moderated, nonlinear relationship } \\
\hline & $b$ & $S E$ & $b$ & $S E$ & $b$ & $S E$ \\
\hline Age & $-0.015^{*}$ & 0.007 & $-0.016^{*}$ & 0.007 & $-0.015^{*}$ & 0.007 \\
\hline $\begin{array}{l}\text { Interdepartmental } \\
\text { collaboration }\end{array}$ & & & & & 0.092 & 0.076 \\
\hline $\begin{array}{l}\text { Age } \times \text { interdepartmental } \\
\text { collaboration }\end{array}$ & & & & & $0.018^{*}$ & 0.008 \\
\hline $\begin{array}{l}\text { Age squared } \times \\
\text { interdepartmental } \\
\text { collaboration }\end{array}$ & & & & & -0.001 & 0.001 \\
\hline$R^{2}$ & 0.233 & & 0.244 & & 0.265 & \\
\hline
\end{tabular}
age $(-0.015, p=0.02)$ and age-squared $(-0.001, p=0.02)$ were significantly related to innovative behavior. Interdepartmental collaboration $(-0.092, n s$.) and its interaction with the squared term of age

TABLE 2 Unstandardized solution of regression analyses

Note. $N=305$. Unstandardized solutions of regressions analyses. Results are clustering errors at team level and without impotent controls. Results showed that the following controls had significant effects $(p<0.05)$ on our dependent variable: liking $(0.40)$, gender $(-0.29)$, and organizational level $(0.76)$. Values in bold are relevant to tests of hypotheses. 


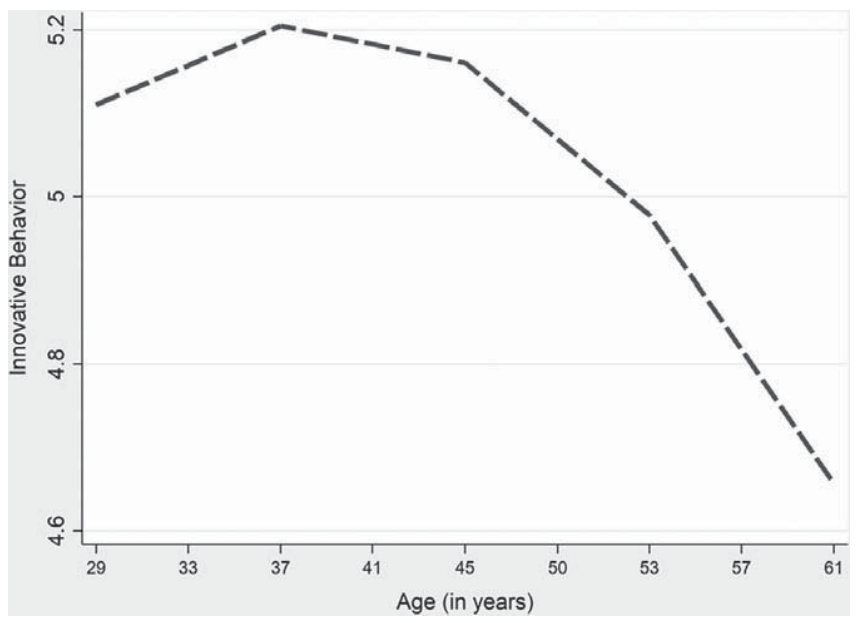

FIGURE 3 Nonlinear relationship between age and innovative behavior

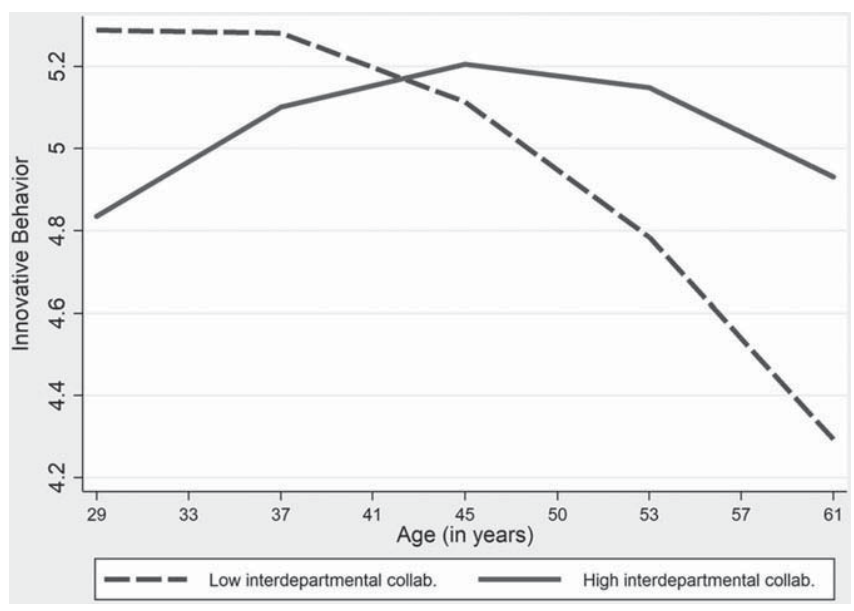

FIGURE 4 Relationship between age and innovative behavior at low and high values of interdepartmental collaboration

$\left(\right.$ Mean $\left._{\text {InterCollab }} \pm 1 \mathrm{SD}_{\text {InterCollab }}\right)$

$(-0.001, n s$.$) were not significantly related to innovative behavior. In$ contrast, as we expected, the interaction between interdepartmental collaboration and age was positively and significantly related to innovative behavior $(0.018, p=0.02)$. These findings suggest that interdepartmental collaboration moderates the relationship between age and innovative behavior in such a way that the vertex of the curve should change location depending on the value of interdepartmental collaboration (Haans et al., 2016).

Figure 4 illustrates the relationship between age and innovative behavior at high and low values of interdepartmental collaboration (i.e., $M_{\text {InterColab }}+1 S D_{\text {InterColab }}$ and $M_{\text {InterColab }}-1 S D_{\text {InterColab }}$, respectively). The vertex moved to the right when interdepartmental collaboration was high, and age and innovative behavior had a negative relationship only when interdepartmental collaboration was low. ${ }^{6}$

Following procedures similar to the ones reported above, we then proceeded to test the slopes (i.e., the differences in innovative behavior between point estimates) at low, intermediate, and high age values with respect to the corresponding vertex for high and low values of interdepartmental collaboration. As we expected, when interdepartmental collaboration was low, the slope at the intermediate values of age was not significant $(p=0.58)$. In contrast, at higher age values, the slope was negative and significantly different from zero ( $F$ $(1,43)=7.46 ; p=0.009)$. When interdepartmental collaboration was high, the slope between points at low age was positive and significant; $F(1,43)=4.16, p=0.05$. In contrast, the slope at intermediate age values was not significant ( $p=0.978$ ), and the slope at high age values was negative but did not differ significantly from zero; $F(1,43)=3.54$; $p=0.067$. These results support Hypothesis 2 .

To test Hypotheses $3 a$ and $b$, we ran regressions, one for each of our final dependent variables, including as predictors the age terms (age and age-squared), their interactions with interdepartmental collaboration, and the hypothesized mediator, as in Equation 6.

$z_{a-c i}=\beta_{0}+\beta_{1} \cdot x_{i}+\beta_{2} \cdot x_{i}^{2}+\beta_{3} \cdot w_{i}+\beta_{4} \cdot x_{i} \cdot w_{i}+\beta_{5} \cdot x_{i}^{2} \cdot w_{i}+y_{i}+e$,

where, for each individual $i, y_{i}$ is the innovative behavior, $x_{i}$ is age, $w_{i}$ is interdepartmental collaboration, and $z_{a-c i}$ are the three final dependent variables $\left(z_{a i}=\right.$ performance appraisals, $z_{b i}=$ promotability evaluations, and $z_{c i}=$ variable pay allocations).

In accordance with our predictions, performance appraisals $(0.85$, $p<0.001)$, promotability evaluations $(0.93, p<0.001)$, and variable pay allocations $(0.24, p<0.001)$ had positive and significant relationships with innovative behavior. The direct effects of the interaction terms (i.e., $x_{i} \cdot w_{i}$ and $x_{i}{ }^{2} \cdot w_{i}$ ) were not significantly related to any of our final outcomes. Interpersonal liking was positively and significantly related to performance appraisals (1.23, $p<0.001)$, promotability $(0.77, p<0.001)$, and variable pay allocations $(0.11, p=0.030)$. Moreover, age (0.02), the squared term of age $(-0.002)$, and organizational level (0.91) had significant relations with variable pay allocation. These significant paths were retained in subsequent moderated mediation analyses. These results suggest that innovative behavior fully mediated the influence of age on performance appraisals and promotability but only partly mediated the influence of age on variable pay.

We then tested our moderated mediation hypotheses (Hypotheses $4 \mathrm{a}$ and b) using generalized SEM (gsem) models, allowing us to test two regressions simultaneously (Equations 3 and 6) with binary (promotability) and ordinal (performance appraisal) outcome variables. We used a bootstrapping procedure to construct $95 \%$ biascorrected confidence intervals $(\mathrm{Cl})$ to explore these conditional indirect effects at different values of the moderator (Edwards \& Lambert, 2007). ${ }^{7}$

In accordance with Hypothesis 4a, when interdepartmental collaboration was low, age lowered performance appraisals through innovative behavior at high age values with respect to the vertex of the curve, and the $\mathrm{Cl}$ of the bootstrapped analyses excluded zero $(-0.50$, $p=0.005,95 \% \mathrm{Cl}=[-0.85,-0.16])$. In contrast, the indirect effects at intermediate age values with respect to the vertex were not significant (0.02), and the $\mathrm{Cl}$ included zero $(95 \% \mathrm{Cl}=[-0.08,0.11])$. These results suggest that, when interdepartmental collaboration was low, age indirectly lowered performance appraisals through innovative behavior only at high age values. In contrast, age was not significantly related to performance appraisals through innovative behavior at any age value when interdepartmental collaboration was high $(0.14$, -0.02 , and -0.18 , ns., for low, intermediate, and high age values with respect to the vertex, respectively). 
Age also lowered variable pay indirectly through innovative behavior when interdepartmental collaboration was low and age was high: $-0.22,95 \% \mathrm{Cl}=[-0.39,-0.05]$. In contrast, the indirect effect at intermediate age values was not significant $(0.01, n s$.$) . When inter-$ departmental collaboration was high, the indirect effects were not significant at any age value $(0.05,-0.01$, and -0.07 , ns., for low, intermediate, and high age values, respectively). These results support Hypothesis $4 a^{8}$

The results showed a similar pattern for promotability evaluations (H4b). When interdepartmental collaboration was low, the indirect effect at high age values was negative (-0.61), and the $\mathrm{Cl}$ excluded zero $(95 \% \mathrm{Cl}=[-1.11,-0.13])$ and was not significant at intermediate age values $(0.02, n s$.$) . In contrast, when collaboration was high, the \mathrm{Cl}$ at all age values were not significant $(0.16,-0.03$, and -0.22 , ns., for low, intermediate, and high age values, respectively). These results suggest that the indirect effect of age on promotability was negative only when interdepartmental collaboration was low and age values were high.

\subsection{Robustness checks}

Like other scholars (Carnabuci \& Diószegi, 2015; Scott \& Bruce, 1994; Welbourne et al., 1998), we rely on supervisory ratings to measure employees' innovative behavior. The age literature proposes that negative age stereotypes portray older workers as less technologically savvy, less productive, and more resistant to change (see Posthuma \& Campion, 2009, for an overview), potentially biasing their evaluations in general (Ferris, Yates, Gilmore, \& Rowland, 1985). Thus, it seems reasonable to predict that, because of these biases, older employees will receive lower ratings of innovative behavior from their supervisors than younger employees. However, in this paper, we assume that the actual innovative behavior of older employees can be enhanced by interdepartmental collaboration. The fact that we found support for our moderating Hypothesis 2 is in line with the prediction that age is associated with declines in actual innovative capability. Next, we performed further analyses in an attempt to assess the soundness of our predictions.

\subsubsection{Self-assessed innovation as alternative mediator}

As we were not able to measure participants' innovation directly, to rule out the possibility that our results are driven exclusively by supervisors' prejudices against older workers with respect to their innovative behavior, we asked each participant to self-assess his or her innovative behavior and interdepartmental collaboration at Time 1. We used the same six-item scale by Scott and Bruce (1994) that we used for supervisor assessments, adapting the items to the first person (e.g., "I generate creative ideas") ( $\alpha=0.93$ ).

The curvilinear model did not explain self-assessed innovation significantly better than the linear one, so we used the linear model in subsequent analyses. Our results showed that the interaction between age and interdepartmental collaboration significantly predicted self-assessed innovative behavior $(0.02, p<0.05)$. A simple slopes analysis demonstrated that, when interdepartmental collaboration was low, age had a negative relationship with self-assessed innovative behavior $(-0.03, S E=0.01, p<0.001)$. In contrast, when collaboration was high, the simple slope was not significant (0.01, SE = 0.01 , ns.). The fact that we found a negative relationship between age and innovative behavior, rated both by supervisor and by self, only when interdepartmental collaboration was low is reassuring. Selfassessed innovative behavior had positive and significant relationships with performance appraisals and promotability but not with variable pay.

\subsubsection{Interpersonal liking and age}

Interpersonal liking was positively related in our sample with innovative behavior as well as with performance and promotability evaluations. One reading of these results is that individuals who lack innovative skills are judged less positively in part because they are less liked in their work roles. We also assessed the possibility that older workers were, in general, less liked than younger ones. Results showed that neither age $(-0.01, n s$.$) nor squared age (0.00, n s$.$) pre-$ dicted liking above and beyond controls. This suggests that prejudices toward older workers could not be explained through diminished interpersonal liking.

In addition, we explored if older employees high in interdepartmental collaboration were perceived as more likeable than those who did not collaborate and if this interpersonal liking might drive supervisors' ratings of innovative behavior. Because the age quadratic model did not predict liking significantly better than the linear model $\left(\Delta R^{2}=\right.$ $0.00, F(1,43)=42, p=0.52$ ), we introduced into the linear model interdepartmental collaboration and its interaction with age as predictors of liking. Neither of these terms was significantly related to liking (0.08 and -0.002 , ns., respectively). These results suggest that the effect of age on innovative behavior moderated by interdepartmental collaboration cannot be explained by interpersonal liking and hint that interpersonal liking cannot explain the age-innovative behavior relationship we found in our study.

\subsubsection{Age of the supervisor and age biases}

Finally, as an additional robustness check, we modeled the age of the supervisor as an additional moderator of the relationship between employee age and innovative behavior. Research has shown that negative stereotypes are strongest when raters do not belong to the group suffering discrimination (e.g., for males rating professional women, Eagly \& Karau, 2002; for young raters evaluating older employees, Ferris, Judge, Chachere, \& Liden, 1991; Ng \& Feldman, 2008). We tested whether there were significant paths between innovative behavior and the interactions "Employee age $X$ Interdepartmental collaboration $X$ Supervisor age" and "Employee age-squared $X$ Interdepartmental collaboration X Supervisor age" in the linear and quadratic models, respectively. Neither of these interactions was significant. These results suggest that the innovative behavior of older employees was not rated differently by younger and older supervisors.

\section{DISCUSSION}

Does employees' age reduce innovative behavior and performance and promotability evaluations? Our results show that these effects 
are not as straightforward as previously thought. In fact, older workers high in interdepartmental collaboration were assessed to be as innovative as young employees. Only when interdepartmental collaboration was low were older employees punished with lower performance and promotability assessments based on reduced innovative behavior. These results have a number of theoretical and practical implications.

\subsection{Theoretical contributions}

Our findings contribute to the literature on age stereotypes and discrimination (Ng \& Feldman, 2012; Posthuma \& Campion, 2009) in the workplace. Previous research has focused on examining negative effects of age on perceptions of performance and individual-level outcomes, with mixed results (Kanfer \& Ackerman, 2004; McEvoy \& Cascio, 1989; $\mathrm{Ng} \&$ Feldman, 2008; Waldman \& Avolio, 1986; Warr, 1994). Several experimental studies have tested age effects on selection and other personnel decisions (see Finkelstein, Burke, \& Raju, 1995, for a review). Fewer studies have explored the mechanisms underlying the negative consequences of age in organizational settings (for two notable exceptions, see Avolio, Waldman, \& McDaniel, 1990; Ferris et al., 1991). This study shows that innovative behavior is one such mediator. However, while innovative behavior fully mediated the relationship between age and promotability as well as performance appraisals, it only partially mediated the relationship between age and variable pay allocations. It may be that status and seniority offset the influence of aging employees' lack of innovativeness on their variable pay. Moreover, we advance this literature by proposing a boundary condition of the effects of age in the workplace and contribute a contingency view of the age stereotypical perceptions in the workplace.

By doing so, our study serves to clarify some of the theoretical and empirical inconsistencies in the literature on age and innovation-related behaviors, which has mostly assessed age only as a control variable (see Binnewies, Ohly, \& Niessen, 2008, for an exception) and has found mixed results, ranging from a negative association (Axtell et al., 2000; Isaksson \& Johansson, 2000; Janssen, 2004, 2005; Pieterse, Van Knippenberg, Schippers, \& Stam, 2010; Riolli-Saltzman \& Luthans, 2001; Scott \& Bruce, 1994) to null findings reported in a meta-analysis ( $\mathrm{Ng} \&$ Feldman, 2008). To explain these inconsistent findings, we tested both a curvilinear relation between age and innovative behavior and a potential boundary condition (interdepartmental collaboration). Our results show that age reduces innovative behavior only after a peak in the late 30s (37.22 years in our sample). To the best of our knowledge, this is the first study providing support for this nonlinear relationship-where innovation is conceived as including idea implementation, as distinct from the narrower concept of creativity as idea generation-in an organizational setting.

Our results suggest that older employees can compensate for their decline in innovative ability through the social strategy of interdepartmental collaboration, which fosters diversity of knowledge. This finding complements research in organizational behavior, showing that spanning the boundary of one's function at work triggers innovation (Ancona \& Caldwell, 1992a). Scholars in aging research have hinted that older employees can develop collaborative structures to compensate for specific declines in skills (Hansson et al., 1997), and social support is generally associated with continued functioning in old age (Dixon \& Backman, 1995; Hansson et al., 1997; Rowe \& Kahn, 1987).
Finally, by testing a boundary condition of the effects of age, this study contributes to a contingency view of age in the workplace (Baltes \& Baltes, 1990; Kanfer \& Ackerman, 2004). Older employees have reported higher subjective ratings of competence maintenance using compensatory strategies (Abraham \& Hansson, 1995). They also make efforts to be good citizens and engage in less counterproductive behavior, which has been interpreted as a conscious attempt to compensate for their losses in technical performance (Chapman \& Hayslip, 2006; Ng \& Feldman, 2008; Okun, Barr, \& Herzog, 1998). Much writing that deals with job obsolescence suggests focusing on one of these compensatory mechanisms: the social context that, over time, builds resources to prevent declines in technical performance (Fossum, Arvey, Paradise, \& Robbins, 1986; Howard \& Bray, 1988). Binnewies et al. (2008) have shown that the relationship between age and creativity is moderated by social support for creativity (i.e., the extent to which supervisors and colleagues encourage employees to be creative). They found that age reduced employees' creativity when social support was low but not when it was high. The present study contributes to this literature by showing that interdepartmental collaboration is a key social contingency that explains how age affects innovative behavior.

\subsection{Limitations}

Like all studies, this study is subject to limitations that point toward new directions for future research. First, we were not able to measure innovation objectively. Although we ran various robustness checks (including retesting our model with self-reported innovation, and controlling for interpersonal liking), we certainly cannot completely disregard the possibility of age biases in supervisors' ratings of innovative behavior. For example, when older employees are actively networking and collaborating with others, supervisors will view these older workers in a more positive light because networking and collaborating with others signals commitment and proactivity (Thomas, Whitman, \& Viswesvaran, 2010). What follows is that interdepartmental collaboration might not reduce the negative effects of age on cognitive ability (which affect innovative behavior) but just the negative age stereotypes held by supervisors toward older employees in general. Still, the fact that interdepartmental collaboration completely removes the (behavioral and/or perceptual) negative effects of age on personnel outcomes is a valuable finding with significant theoretical and practical implications. Additional studies are needed to pin down these relationships further.

Second, in an international social work organization, interdepartmental collaboration might be particularly relevant because social workers are expected to propose creative solutions to cope with changing societal challenges. However, collaboration is assumed to facilitate individual performance even in the most technical professions (Bancino \& Zevalkink, 2007; Dixon, Belnap, Albrecht, \& Lee, 2010). Thus, we expect our results to generalize to other organizations. Further research is needed to establish the generalizability of our results to more industries. It is worth noting that, although the organization studied here has a clear international orientation (it operates worldwide and has offices on three continents) and is among the top five social work organizations in the world in terms of investments, all our data come from managers working in Southern Europe, and more than $70 \%$ of them were women. Future research 
should replicate our findings in other cultural contexts and using samples with more equal gender distributions.

Third, we focus on the idea generation and implementation components of innovation. Nevertheless, the innovation paradox (Miron-Spektor, Erez, \& Naveh, 2011) suggests that idea creation does not always go hand in hand with idea implementation, so further studies may be needed to assess the consequences of age at these different stages. Some jobs may require substantial novelty and creativity that cannot be fostered by previous experience (Kanfer \& Ackerman, 2004). Moreover, it is plausible that, while certain personal characteristics of older workers (e.g., cognitive styles, attention to detail) can help them to implement new ideas, they can harm idea generation capability (Carnabuci \& Diószegi, 2015). Future research needs to clarify the mediating mechanisms that explain the effects of age on the different innovation components.

Fourth, we selected only one moderator, interdepartmental collaboration. However, other individual strategies (e.g., increased effort; Kanfer \& Ackerman, 2004) and/or social or organizational characteristics, such as organizational identification, can compensate for declining abilities. Future research can include other strategies in more comprehensive models to account for the consequences of age at work. Moreover, there are many sources of diverse experiences that can foster innovation (Milliken, Bartel, \& Kurtzberg, 2003). We were principally concerned with varied task and functional experience; future research should consider additional diversity-related personal and group characteristics, such as personality or goal orientation or the age of teammates, as additional moderators.

Finally, the nature of our data did not permit us to disentangle possible dynamic relationships among age, innovative behavior, and interdepartmental collaboration and their consequences over time. For example, it is possible that innovative behavior increases interdepartmental collaboration at the individual level. Additional longitudinal studies are needed to test the dynamic relationships among our focal variables. Relatedly, collinearity between the variables in our model could have biased our results. While the variance inflation factors that we found were not troubling, future research can use alternative measures of our variables. Finally, because older workers are suggested to make "deliberate efforts to collaborate with others" (Baltes \& Baltes, 1990), age is likely to affect innovative behavior as well as interdepartmental collaboration. We tested a model adding a nonhypothesized path from age to interdepartmental collaboration. Results showed that this path was not significant $(0.01$, $p=0.14$ ) and that our core relationships remained significant. These results suggest that the path from age to interdepartmental collaboration should not be retained. Future research should explore this issue in more depth. However, due to our data collection procedures, we cannot completely rule out the possibility that reverse causality affects our results. Future research should aim at replicating our findings using other research measures and procedures.

\subsection{Practical implications}

Our results offer various practical implications for HR management and, more broadly, for age-friendly organizational practices. The leadership literature has highlighted that one of the most difficult challenges that individuals encounter in their careers within organizations is to let go of the "individual contributor" mentality in order to incorporate social behaviors, such as networking and collaboration, as key ingredients for their own job success (e.g., Charan, Drotter, \& Noel, 2000). HR management and senior managers can facilitate this mentality change by incorporating "collaboration" across business areas and departments as an explicit job requirement.

Collaboration often takes time and effort, but organizations that truly care about age equality and diversity should make sure to establish procedures and environments (e.g., an open office architecture) that promote, either formally or informally, chances to collaborate across departments. For example, HR can carefully form functionally diverse work teams that boost the innovative behavior of older employees. In addition, organizations can make deliberate efforts to define innovation as not just an outcome but also a process that encompasses both idea generation and idea implementation. Instead of reinforcing the myth of the successful "lonely innovator" by applauding idea generation only, they can openly celebrate collaborative efforts that lead to the successful implementation of new ideas. Older employees are concerned with giving back to others and have a high need for generativity (McAdams, 2001). Fostering collaboration can help them share their knowledge and experience, ultimately serving to maintain their work motivation and engagement at healthy levels.

Finally, the flip side of our results is that young employees are not "punished" for their low interdepartmental collaboration. In the popular press, successful young professionals (from Steve Jobs to Sheldon Cooper) are often portrayed as cognitively brilliant but lacking in interpersonal skills (Castells, 1999; Cringely, 1996). If their noncollaborative attitudes are not punished, once they make it to the top, these attitudes can eventually cascade down. Dealing with "age issues" should not be put exclusively on older employees' shoulders; instead, HR and senior management should play a key role in promoting age-diverse places to work. Organizations can make a conscious choice about whether "being collaborative" matters for employees' success. If the organization chooses to take collaboration into account, a noncollaborative attitude should constitute a liability in both younger and older employees' evaluations.

\section{CONCLUSION}

Age does not always go hand in hand with lack of innovation and low competence evaluations. Interdepartmental collaboration is the key to understanding when and why older employees fail to innovate and therefore receive lower performance appraisals, promotability assessments, and annual bonuses. Older employees with low interdepartmental collaboration are less innovative and perceived as less competent. In contrast, the "age handicap" vanishes when older employees collaborate with other members of their organizations. Organizations can and should foster collaboration among their members, either formally or informally. Doing so is necessary to combat age discrimination and ensure equal career opportunities for all employees, regardless of their age.

\section{ENDNOTES}

${ }^{1}$ Although arguably functional business areas (e.g., marketing) can be broader than organizational departments (e.g., retail marketing, product marketing), we focus on collaboration across departments because departments usually have clearer boundaries than functional areas, 
possessing their own chain of command and their own responsibilities and work processes that require specialized knowledge and expertise.

${ }^{2}$ The conclusions with respect to our hypotheses are identical if we use either regressions or gsem approaches to data analysis.

${ }^{3}$ Significant controls $(p<0.05)$ in Model 2 were interpersonal liking (0.40), gender (-0.29), and organizational level (0.76).

${ }^{4}$ Location of vertex $=(-$ linear coefficient $/ 2 *$ quadratic coefficient $)$.

${ }^{5}$ In particular, we tested the slopes (a) at low age values with respect to the vertex: (a) at age values lower than minus 0.5 SDs below the vertex, $a_{1}$; (b) at intermediate age values: between minus and plus 0.5 $S D$ s with respect to the vertex; and (c) at high age values: higher than plus $0.5 \mathrm{SDs}$.

${ }^{6} \mathrm{We}$ calculated the vertices of the age-innovation curves at low and high interdepartmental collaboration following the formula provided by Haans et al. (2016, p. 20). As shown in Figure 4, the turning point moved from 29 years (when interdepartmental collaboration was low) to 45 years, when collaboration was high. Please note that, in subsequent analyses, we were not able to test the slope of the ageinnovative behavior curve, when interdepartmental collaboration was low, at low age values with respect to the vertex (lower than 29 years). This is because of age range restrictions in our sample (that had a minimum value of 27 years).

${ }^{7}$ We performed Hausman tests to verify that potential endogeneity did not bias the estimated coefficients (Antonakis, Bendahan, Jacquart, \& Lalive, 2010). In particular, we tested whether the correlations of the error terms between the mediator and each of the three final dependent variables were significant. None of the Hausman tests were significant $\chi^{2}(1)=0.61,2.24$, and 3.05 , ns., for correlations between innovative behavior and variable pay, promotability, and performance, respectively), suggesting that endogeneity was not challenging the validity of our conclusions.

$t / s b-2 p t$ Interestingly, age and the squared term of age had significant and positive direct relationships with variable pay $(0.02$ and -0.002 , respectively; $p<0.01$ ). When interdepartmental collaboration was low, the total effects of age on variable pay were positive and significant at low and intermediate values. In contrast, the total effects were not significant at high age values. These results suggest that the positive direct effects of age and the squared term of age on variable pay mitigated the negative indirect effects via innovative behavior at high age values. When interdepartmental collaboration was high, age had positive and significant total effects at all age intervals. These unexpected results suggest that, in formulating our theoretical model, we might have overlooked other mechanisms that drive a positive effect of age on variable pay. For example, the seniority or acquired status of older workers in the organization may compensate for the negative effect of their low innovative behavior even when they are not willing to collaborate with others.

\section{REFERENCES}

Abraham, J. D., \& Hansson, R. O. (1995). Successful aging at work: An applied study of selection, optimization, and compensation through impression management. The Journals of Gerontology. Series B, Psychological Sciences and Social Sciences, 50(2), 94-103.

Ackerman, P. L. (1996). A theory of adult intellectual development: Process, personality, interests, and knowledge. Intelligence, 22, 229-259.

Aiken, L. S., \& West, G. (1991). Multiple regressions: Testing and interpreting interactions. Thousand Oaks, CA: Sage.

Alexander, L., \& Van Knippenberg, D. (2014). Teams in pursuit of radical innovation: A goal orientation perspective. Academy of Management Review, 39(4), 423-438.
Allen, T. J., \& Cohen, S. I. (1969). Information flow in research and development laboratories. Administrative Science Quarterly, 20, 12-19.

Amabile, T. M. (1983). The social psychology of creativity: A componential conceptualization. Journal of Personality and Social Psychology, 45(2), 357-376.

Amabile, T. M. (1988). A model of creativity and innovation in organizations. Research in Organizational Behavior, 10(1), 123-167.

Amabile, T. M. (1993). What does a theory of creativity require? Psychological Inquiry, 4(3), 179-181.

American Association of Retired Persons (AARP). (2014). Forced out, older workers are fighting back. Retrieved from http://www.aarp. org/work/on-the-job/info-2014/workplace-age-discriminationinfographic.html

American Association of Retired Persons (AARP). (2017). Age discrimination goes online: 50 years after the landmark legislation to protect older workers, bias is on the rise. Retrieved from https://www.aarp.org/work/ working-at-50-plus/info-2017/age-discrimination-online-fd.html

Ancona, D. G., \& Caldwell, D. F. (1988). Beyond task and maintenance: Defining external functions in groups. Group \& Organization Studies, 13 (4), 468-494.

Ancona, D. G., \& Caldwell, D. F. (1992a). Bridging the boundary: External activity and performance in organizational teams. Administrative Science Quarterly, 37, 634-665.

Ancona, D. G., \& Caldwell, D. F. (1992b). Demography and design: Predictors of new product team performance. Organization Science, 3(3), 321-341.

Antonakis, J., Bendahan, S., Jacquart, P., \& Lalive, R. (2010). On making causal claims: A review and recommendations. The Leadership Quarterly, 21(6), 1086-1120.

Arvey, R. D., \& Murphy, K. R. (1998). Performance evaluation in work settings. Annual Review of Psychology, 49(1), 141-168.

Aryee, S., Walumbwa, F. O., Zhou, Q., \& Hartnell, C. A. (2012). Transformational leadership, innovative behavior, and task performance: Test of mediation and moderation processes. Human Performance, 25(1), 1-25.

Austin, J. R. (2003). Transactive memory in organizational groups: The effects of content, consensus, specialization, and accuracy on group performance. Journal of Applied Psychology, 88(5), 866-878.

Avolio, B. J., Waldman, D. A., \& McDaniel, M. A. (1990). Age and work performance in nonmanagerial jobs: The effects of experience and occupational type. Academy of Management Journal, 33(2), 407-422.

Axtell, C. M., Holman, D. J., Unsworth, K. L., Wall, T. D., Waterson, P. E., \& Harrington, E. (2000). Shopfloor innovation: Facilitating the suggestion and implementation of ideas. Journal of Occupational and Organizational Psychology, 73(3), 265-285.

Baer, M., \& Oldham, G. R. (2006). The curvilinear relation between experienced creative time pressure and creativity: Moderating effects of openness to experience and support for creativity. Journal of Applied Psychology, 91(4), 963-970.

Baltes, P. B., \& Baltes, M. M. (1990). Psychological perspectives on successful aging: The model of selective optimization with compensation. In P. B. Baltes \& M. M. Baltes (Eds.), Successful aging: Perspectives from the behavioral sciences (pp. 1-34). New York, NY: Cambridge University Press.

Bancino, R., \& Zevalkink, C. (2007). Soft skills: The new curriculum for hard-core technical professionals. Techniques: Connecting Education and Careers, 82, 20-22.

Barsalou, L. W. (1983). Ad hoc categories. Memory and Cognition, 11, 211-227.

Bartram, D. (2005). The great eight competencies: A criterion-centric approach to validation. Journal of Applied Psychology, 90(6), $1185-1205$.

Becker, T. E. (2005). Potential problems in the statistical control of variables in organizational research: A qualitative analysis with recommendations. Organizational Research Methods, 8(3), 274-289.

Bentler, P. M., \& Dudgeon, P. (1996). Covariance structure analysis: Statistical practice, theory, and directions. Annual Review of Psychology, 47(1), 563-592.

Binnewies, C., Ohly, S., \& Niessen, C. (2008). Age and creativity at work: The interplay between job resources, age and idea creativity. Journal of Managerial Psychology, 23(4), 438-457.

Bollen, K. A. (1989). Structural equation with latent variables. New York, NY: Wiley. 
Brown, J. S., \& Duguid, P. (1991). Organizational learning and communities-of-practice: Toward a unified view of working, learning, and innovation. Organization Science, 2(1), 40-57.

Campbell, D. (1960). Blind variation and selective retention in crative thought as in other knowledge processes. Psychological Review, 67, 380-400.

Cardy, R. L., \& Dobbins, G. H. (1986). Affect and appraisal accuracy: Liking as an integral dimension in evaluating performance. Journal of Applied Psychology, 71(4), 672-678.

Carmeli, A., Gelbard, R., \& Reiter-Palmon, R. (2013). Leadership, creative problem-solving capacity, and creative performance: The importance of knowledge sharing. Human Resource Management, 52(1), 95-121.

Carnabuci, G., \& Diószegi, B. (2015). Social networks, cognitive style, and innovative performance: A contingency perspective. Academy of Management Journal, 58(3), 881-905.

Castells, M., \& United Nations Research Institute for Social Development. (1999). Information technology, globalization and social development (Vol. 114). Geneva, Switzerland: United Nations Research Institute for Social Development.

Cattell, R. B. (1943). The measurement of adult intelligence. Psychological Bulletin, 40(3), 153-193.

Cattell, R. B. (1987). Intelligence: Its structure, growth, and action. New York, NY: North Holland.

Chapman, B. P., \& Hayslip, B. (2006). Emotional intelligence in young and middle adulthood: Cross-sectional analysis of latent structure and means. Psychology and Aging, 21, 411-418.

Charan, R., Drotter, S., \& Noel, J. (2000). The leadership pipeline: How to build the leadership powered company. San Francisco, CA: Jossey-Bass.

Cheung, G. W., \& Lau, R. S. (2008). Testing mediation and suppression effects of latent variables: Bootstrapping with structural equation models. Organizational Research Methods, 11(2), 296-325.

Cirillo, B., Brusoni, S., \& Valentini, G. (2013). The rejuvenation of inventors through corporate spinouts. Organization Science, 25(6), 1764-1784.

Conger, J. A., \& Kanungo, R. N. (1987). Toward a behavioral theory of charismatic leadership in organizational settings. Academy of Management Review, 12(4), 637-647.

Conway, J. M., \& Lance, C. E. (2010). What reviewers should expect from authors regarding common method bias in organizational research. Journal of Business and Psychology, 25, 325-334.

Craik, F. I., \& Bialystok, E. (2006). Cognition through the lifespan: Mechanisms of change. Trends in Cognitive Sciences, 10(3), 131-138.

Cringely, R. X. (1996). Accidental empires. New York, NY: Harper Business.

Cuddy, A. J., Norton, M. I., \& Fiske, S. T. (2005). This old stereotype: The pervasiveness and persistence of the elderly stereotype. Journal of Social Issues, 61(2), 267-285.

Dane, E. (2010). Reconsidering the trade-off between expertise and flexibility: A cognitive entrenchment perspective. Academy of Management Review, 35(4), 579-603.

Dixon, R. A., \& Backman, L. (1995). Compensating for psychological deficits and declines: Managing losses and promoting gains. Mahwah, NJ: Erlbaum.

Dixon, J., Belnap, C., Albrecht, C., \& Lee, K. (2010). The importance of soft skills. Corporate Finance Review, 14(6), 35-58.

Eagly, A. H., \& Karau, S. J. (2002). Role congruity theory of prejudice toward female leaders. Psychological Review, 109(3), 573-598.

Eder, P., \& Sawyer, J. E. (2007, April). A meta-analytic examination of employee creativity. Paper presented at the 22nd Annual Conference, Society of Industrial and Organizational Psychology (SIOP), New York, NY.

Edwards, J. R. (1994). The study of congruence in organizational behavior research: Critique and a proposed alternative. Organizational Behavior and Human Decision Processes, 58(1), 51-100.

Edwards, J. R., \& Lambert, L. S. (2007). Methods for integrating moderation and mediation: A general analytical framework using moderated path analysis. Psychological Methods, 12(1), 1-22.

Edwards, J. R., \& Parry, M. E. (1993). On the use of polynomial regression equations as an alternative to difference scores in organizational research. Academy of Management Journal, 36(6), 1577-1613.

Farrell, C. (2017, February 14). The age discrimination law at 50: A mixed bag. Forbes.

Feldman, D. C., \& Weitz, B. A. (1988). Career plateaus reconsidered. Journal of Management, 14(1), 69-80.

Ferris, G. R., Judge, T. A., Chachere, J. G., \& Liden, R. C. (1991). The age context of performance-evaluation decisions. Psychology and Aging, 6 (4), 616-622
Ferris, G. R., Yates, V. L., Gilmore, D. C., \& Rowland, K. M. (1985). The influence of subordinate age on performance ratings and causal attributions. Personnel Psychology, 38(3), 545-557.

Finkelstein, L. M., Burke, M. J., \& Raju, M. S. (1995). Age discrimination in simulated employment contexts: An integrative analysis. Journal of Applied Psychology, 80(6), 652-663.

Fiske, S. T., Cuddy, A. J., \& Glick, P. (2007). Universal dimensions of social cognition: Warmth and competence. Trends in Cognitive Sciences, 11(2), 77-83.

Fiske, S. T., \& Taylor, S. E. (1991). Social cognition (2nd ed.). New York, NY: McGraw-Hill.

Fossum, J. A., Arvey, R. D., Paradise, C. A., \& Robbins, N. E. (1986). Modeling the skills obsolescence process: A psychological/economic integration. Academy of Management Review, 11(2), 3613-3374.

Grosser, T. J., Venkataramani, V., \& Labianca, G. J. (2017). An alter-centric perspective on employee innovation: The importance of alters' creative self-efficacy and network structure. Journal of Applied Psychology, 102 (9), 1360-1374.

Haans, R. F., Pieters, C., \& He, Z. L. (2016). Thinking about U: Theorizing and testing $\mathrm{U}$-and inverted $\mathrm{U}$-shaped relationships in strategy research. Strategic Management Journal, 37(7), 1177-1195.

Hansson, R. O., Dekoekkoek, P. D., Neece, W. M., \& Patterson, D. W. (1997). Successful aging at work: Annual review, 1992-1996: The older worker and transitions to retirement. Journal of Vocational Behavior, 51(2), 202-233.

Hargadon, A. B., \& Bechky, B. A. (2006). When collections of creatives become creative collectives: A field study of problem solving at work. Organization Science, 17(4), 484-500.

Heavey, C., Simsek, Z., \& Fox, B. C. (2015). Managerial social networks and ambidexterity of SMEs: The moderating role of a proactive commitment to innovation. Human Resource Management, 54(1), 201-221.

Hoegl, M., Weinkauf, K., \& Gemuenden, H. G. (2004). Interteam coordination, project commitment, and teamwork in multiteam R\&D projects: A longitudinal study. Organization Science, 15(1), 38-55.

Horn, J. L., \& Cattell, R. B. (1967). Age differences in fluid and crystallized intelligence. Acta Psychologica, 26, 107-129.

Howard, A., \& Bray, D. W. (1988). Managerial lives in transition: Advancing age and changing times. New York, NY: Guilford Press.

Howell, J. M., \& Shea, C. M. (2006). Effects of champion behavior, team potency, and external communication activities on predicting team performance. Group \& Organization Management, 31(2), 180-211.

Hoyle, R. H., \& Smith, G. T. (1994). Formulating clinical research hypotheses as structural equation models: A conceptual overview. Journal of Consulting and Clinical Psychology, 62(3), 429-440.

Isaksson, K., \& Johansson, Q. (2000). Adaptation to continued work and early retirement following downsizing: Long-term effects and gender differences. Journal of Occupational and Organizational Psychology, 73, 241-256.

Janssen, O. (2001). Fairness perceptions as a moderator in the curvilinear relationships between job demands, and job performance and job satisfaction. Academy of Management Journal, 44(5), 1039-1050.

Janssen, O. (2004). How fairness perceptions make innovative behavior more or less stressful. Journal of Organizational Behavior, 25, 201-215.

Janssen, O. (2005). The joint impact of perceived influence and supervisor supportiveness on innovative behavior. Journal of Occupational and Organizational Psychology, 78, 573-579.

Jones, C. J., \& Meredith, W. (1996). Patterns of personality change across the life span. Psychology and Aging, 11(1), 57-65.

Kanfer, R., \& Ackerman, P. L. (2004). Aging, adult development, and work motivation. Academy of Management Review, 29(3), 440-458.

Kanter, R. M. (1988). Three tiers for innovation research. Communication Research, 15(5), 509-523.

Katz, R. (1981). Career issues in human resource management. Englewood Cliffs, NJ: Prentice-Hall.

Katz, R., \& Allen, T. J. (1982). Investigating the Not Invented Here (NIH) syndrome: A look at the performance, tenure, and communication patterns of $50 \mathrm{R} \& \mathrm{D}$ project groups. $R \& D$ Management, 12(1), 7-20.

Kooij, D. T., De Lange, A. H., Jansen, P. G., Kanfer, R., \& Dikkers, J. S. (2011). Age and work-related motives: Results of a meta-analysis. Journal of Organizational Behavior, 32(2), 197-225.

Kulik, C. T., Ryan, S., Harper, S., \& George, G. (2014). From the editors: Aging populations and management. Academy of Management Journal, 57(4), 929-935. 
Kunze, F., Boehm, S., \& Bruch, H. (2013). Age, resistance to change, and job performance. Journal of Managerial Psychology, 28(7/8), 741-760.

Langer, E. J. (1989). Minding matters: The consequences of mindlessnessmindfulness. Advances in Experimental Social Psychology, 22, 137-173.

Laursen, K., \& Salter, A. (2006). Open for innovation: The role of openness in explaining innovation performance among UK manufacturing firms. Strategic Management Journal, 27(2), 131-150.

Lehman, H. C. (1962). More about age and achievement. Gerontologist, 2 , 141-148.

Mannucci, P. V., \& Yong, K. (2018). The differential impact of knowledge depth and knowledge breadth on creativity over individual careers. Academy of Management Journal, 51(5), 1741-1763.

Maidique, M. A., \& Zirger, B. J. (1985). The new product learning cycle. Research Policy, 14(6), 299-313.

March, J. G. (1991). Exploration and exploitation in organizational learning. Organization Science, 2(1), 71-87.

Mascitelli, R. (2000). From experience: Harnessing tacit knowledge to achieve breakthrough innovation. Journal of Product Innovation Management, 17(3), 179-193.

McAdams, D. P. (2001). Generativity in midlife. In M. E. Lachman (Ed.), Handbook of midlife development (pp. 395-446). New York, NY: Wiley.

McEvoy, G. M., \& Cascio, W. F. (1989). Cumulative evidence of the relationship between employee age and job performance. Journal of Applied Psychology, 74(1), 11-17.

Milliken, F. J., Bartel, C. A., \& Kurtzberg, T. (2003). Diversity and creativity in work groups: A dynamic perspective on the affective and cognitive processes that link diversity and performance. In P. Paulus \& B. Nijstad (Eds.), Group creativity (pp. 32-62). New York, NY: Oxford University Press.

Miron, E., Erez, M., \& Naveh, E. (2004). Do personal characteristics and cultural values that promote innovation, quality, and efficiency compete or complement each other? Journal of Organizational Behavior, 25 (2), 175-199.

Miron-Spektor, E., Erez, M., \& Naveh, E. (2011). The effect of conformist and attentive-to-detail members on team innovation: Reconciling the innovation paradox. Academy of Management Journal, 54(4), 740-760.

Morris, M. G., \& Venkatesh, V. (2000). Age differences in technology adoption decisions: Implications for a changing work force. Personnel Psychology, 53(2), 375-403.

Mumford, M. D., \& Gustafson, S. B. (1988). Creativity syndrome: Integration, application, and innovation. Psychological Bulletin, 103(1), 27-43.

Near, J. P. (1980). The career plateau: Causes and effects. Business Horizons, 23, 53-57.

Neumark, D., Burn, I., \& Button, P. (2017, February 27). Age discrimination and hiring of older workers. FRBSF Economic Letter.

Ng, T. W. H., \& Feldman, D. C. (2008). The relationship of age to ten dimensions of job performance. Journal of Applied Psychology, 93(2), 392-423.

Ng, T. W., \& Feldman, D. C. (2010). Age and innovation-related behavior: The joint moderating effects of supervisor undermining and proactive personality. Journal of Organizational Behavior, 5, 483-606.

Ng, T. W., \& Feldman, D. C. (2012). Evaluating six common stereotypes about older workers with meta-analytical data. Personnel Psychology, 65(4), 821-858.

Nusbaum, E. C., \& Silvia, P. J. (2011). Are intelligence and creativity really so different? Fluid intelligence, executive processes, and strategy use in divergent thinking. Intelligence, 39(1), 36-45.

Okun, M. A., Barr, A., \& Herzog, A. R. (1998). Motivation to volunteer by older adults: A test of competing measurement models. Psychology and Aging, 13, 608-621.

Park, D. C. (1997). Psychological issues related to competence: Cognitive aging and instrumental activities of daily living. In W. Schaie \& S. Willis (Eds.), Social structures and aging (pp. 66-82). Mahwah, NJ: Erlbaum.

Perry-Smith, J. E. (2006). Social yet creative: The role of social relationships in facilitating individual creativity. Academy of Management Journal, 49(1), 85-101.

Perry-Smith, J., \& Mannucci, P. V. (2015). Social networks, creativity, and entrepreneurship. In C. E. Shalley, M. A. Hitt, \& J. Zhou (Eds.), The Oxford handbook of creativity, innovation, and entrepreneurship (pp. 205-224). New York, NY: Oxford University Press.

Pieterse, A. N., Van Knippenberg, D., Schippers, M., \& Stam, D. (2010). Transformational and transactional leadership and innovative behavior:
The moderating role of psychological empowerment. Journal of Organizational Behavior, 31(4), 609-623.

Posthuma, R. A., \& Campion, M. A. (2009). Age stereotypes in the workplace: Common stereotypes, moderators, and future research directions. Journal of Management, 35(1), 158-188.

Powell, W. W., Koput, K. W., \& Smith-Doerr, L. (1996). Interorganizational collaboration and the locus of innovation: Networks of learning in biotechnology. Administrative Science Quarterly, 41(1), 116-145.

Riolli-Saltzman, L., \& Luthans, F. (2001). After the bubble burst: How small high-tech firms can keep in front of the wave. Academy of Management Executive, 15, 114-124.

Rogers, W. H. (1993). Regression standard errors in clustered samples. Stata Technical Bulletin, 13, 19-23.

Romer, P. (1993). Ideas and things: The concept of production is being retooled. The Economist, 328, 70-72.

Rosen, B., \& Jerdee, T. H. (1976). The influence of age stereotypes on managerial decisions. Journal of Applied Psychology, 61(4), 428-432.

Rowe, J. W., \& Kahn, R. L. (1987). Human aging: Usual and successful. Science, 237, 143-150.

Ruth, J. E., \& Birren, J. E. (1985). Creativity in adulthood and old age: Relations to intelligence, sex and mode of testing. International Journal of Behavioral Development, 8(1), 99-109.

Sandberg, B. (2007). Customer-related proactiveness in the radical innovation development process. European Journal of Innovation Management, 10(2), 252-267.

Saris, W. E., \& Gallhofer, I. N. (2007). Design, evaluation, and analysis of questionnaires for survey research. New York, NY: John Wiley \& Sons.

Schaie, K. W. (1994). The course of adult intellectual development. American Psychologist, 49(4), 304-313.

Schaie, K. W. (1996). Intellectual development in adulthood. In J. E. Birren \& K. W. Schaie (Eds.), Handbook of the psychology of aging, 4th Edition (pp. 266-286). San Diego, CA: Academic Press.

Schein, E. H. (1978). Career dynamics: Matching the individual and organizational needs. Reading, MA: Addison-Wesley.

Slocum, J. W., Jr., Cron, W. L., Hansen, R. W., \& Rawlings, S. (1985). Business strategy and the management of plateaued employees. Academy of Management Journal, 28(1), 133-154.

Scott, S. G., \& Bruce, R. A. (1994). Determinants of innovative behavior: A path model of individual innovation in the workplace. Academy of Management Journal, 37(3), 580-607.

Shore, L. M., \& Goldberg, C. B. (2005). Age discrimination in the workplace. In R. L. Dipboye \& A. Colella (Eds.), Discrimination at work: The psychological and organizational bases (pp. 203-225). Mahwah, NJ: Lawrence Erlbaum Associates.

Simonton, D. K. (1988). Age and outstanding achievement: What do we know after a century of research? Psychological Bulletin, 104(2), 251-267.

Singh, J., \& Fleming, L. (2010). Lone inventors as sources of breakthroughs: Myth or reality? Management Science, 56(1), 41-56.

Taylor, A., \& Greve, H. R. (2006). Superman or the fantastic four? Knowledge combination and experience in innovative teams. Academy of Management Journal, 49(4), 723-740.

Teigland, R., \& Wasko, M. M. (2003). Integrating knowledge through information trading: Examining the relationship between boundary spanning communication and individual performance. Decision Sciences, 34(2), 261-286.

The World Bank (2015). Annual report 2015. Retrieved from http://www. worldbank.org/en/about/annual-report-2015

Thomas, J. P., Whitman, D. S., \& Viswesvaran, C. (2010). Employee proactivity in organizations: A comparative meta-analysis of emergent proactive constructs. Journal of Occupational and Organizational Psychology, 83(2), 275-300.

Tortoriello, M., \& Krackhardt, D. (2010). Activating cross-boundary knowledge: The role of Simmelian ties in the generation of innovations. Academy of Management Journal, 53(1), 167-181.

Van Dalen, H. P., Henkens, K., \& Schippers, J. (2009). Dealing with older workers in Europe: A comparative survey of employers' attitudes and actions. Journal of European Social Policy, 19(1), 47-60.

Van de Ven, A. H. (1986). Central problems in the management of innovation. Management Science, 32(5), 590-607.

Van Der Heijden, B. I. J. (2006). Age differences in career activities among higher-level employees in The Netherlands: A comparison between 
profit sector and non-profit sector staff. International Journal of Training and Development, 10(2), 98-120.

Van Veldhoven, M., \& Dorenbosch, L. (2008). Age, proactivity and career development. Career Development International, 13(2), 112-131.

Waldman, D. A., \& Avolio, B. J. (1986). A meta-analysis of age differences in job performance. Journal of Applied Psychology, 71, 33-38.

Warr, P. (1994). Age and job performance. In J. Snel \& R. Cremer (Eds.), Work and aging: A European perspective (pp. 309-322). London, England: Taylor \& Francis.

Warr, P., \& Fay, D. (2001). Age and personal initiative at work. European Journal of Work and Organizational Psychology, 10(3), 343-353.

Wayne, S. J., \& Ferris, G. R. (1990). Influence tactics, affect, and exchange quality in supervisor-subordinate interactions: A laboratory experiment and field study. Journal of Applied Psychology, 75(5), 487-499.

Welbourne, T. M., Johnson, D. E., \& Erez, A. (1998). The role-based performance scale: Validity analysis of a theory-based measure. Academy of Management Journal, 41(5), 540-555.

Zaleznik, A., \& Kets de Vries, M. F. (1975). Power and the corporate mind. Oxford, England: Houghton Mifflin.

Zahra, S. A., \& George, G. (2002). Absorptive capacity: A review, reconceptualization, and extension. Academy of Management Review, 27(2), 185-203.

Zhou, K. Z., \& Li, C. B. (2012). How knowledge affects radical innovation: Knowledge base, market knowledge acquisition, and internal knowledge sharing. Strategic Management Journal, 33(9), 1090-1102.

\section{AUTHOR BIOGRAPHY}

LAURA GUILLÉN is Assistant Professor of Organizational Behavior at ESMT Berlin, where she teaches in the MIM, MBA, and EMBA programs. Her research interests include identity, authenticity, the bright and dark sides of leadership, diversity, and social perceptions. Her work has been presented at numerous international research conferences and published in journals including Organizational Behavior and Human Decision Processes, Organizational Research Methods, and Leadership Quarterly.

FLORIAN KUNZE holds the chair for Organizational Studies at the University Konstanz, Germany. His current research interests include consequences of the demographic change for companies, within-group processes and dynamics in work teams and organizations, leadership research, and evidence-based human resource management strategies.

\section{APPENDIX A. MEASURES}

\section{Interdepartmental collaboration}

1. I collaborate with members of other departments of the organization.

2. I provide access to information and resources needed by other departments in the organization.

3. I know where to access the information and resources that I need for my job.

4. I collaborate with members of other departments to develop and strengthen the quality of my job.

\section{Innovative behavior}

1. Searches out new technologies, processes, techniques, and/or product ideas.

2. Generates creative ideas.

3. Promotes and champions ideas to others.

4. Investigates and secures funds needed to implement new ideas.

5. Develops adequate plans and schedules for the implementation of new ideas.

6. Is innovative.

\section{Performance appraisals}

Rate the extent to which this employee accomplished his/her job goals and responsibilities during the current operating period.

1. Needs development. S/he inconsistently achieves expected performance levels and has not met expectations regarding goal accomplishment. S/he needs to improve to be able to meet his/her targets during the next operating period.

2. Effective. In general, s/he consistently meets his/her goals at adequate levels, although there are some goals that have not been accomplished as demanded.

3. Highly effective. S/he shows high performance levels that often exceed expectations. $\mathrm{S} /$ he is efficient and efficacious accomplishing his/her objectives.

4. Exceptional. S/he consistently and significantly exceeds standards of performance. S/he has achieved far more than what is actually demanded from someone in his/her job. This person truly stands out and clearly and consistently demonstrates a high level of quality and quantity of work that is recognized by others as exceptional.

\section{Promotability evaluations}

Please, indicate whether this employee is ready to take on the next level of responsibilities within the organization. 0 = no; 1 = yes. 